\title{
Lung function and clinical outcome in postpolio patients: a prospective cohort study during 11 years
}

\author{
B. Midgren
}

Lung function and clinical outcome in postpolio patients: a prospective cohort study during 11 years. B. Midgren. CERS Journals Ltd 1997.

ABSTRACT: The object of this investigation was to prospectively study the annual decline in lung function in a cohort of postpolio patients, and to determine the usefulness of initial lung function tests in the prediction of a subsequent poor outcome.

Cross-sectional data were analysed in $\mathbf{5 5}$ patients from the total cohort of 350 survivors of poliomyelitis in our admission area of 550,000 inhabitants. Longitudinal data ( $>5 \mathrm{yrs}$, average $8.9 \mathrm{yrs}$ ) were available for 31 patients.

Seventeen of the patients had a poor outcome (13 were started on domiciliary artificial ventilation and five died from respiratory failure; with one overlap). At the time of entry to the study (on average 4.3 years before the poor outcome), these patients had a lower vital capacity (VC) (43 vs $65 \%$ of predicted; $p<0.01)$ and arterial oxygen tension $\left(\mathrm{Pa}_{\mathrm{a}} \mathrm{O}_{2}\right)(9.9$ vs $11 \mathrm{kPa} ; \mathrm{p}<0.05)$ and a higher arterial carbon dioxide tension $\left(\mathrm{Pa}_{\mathrm{a}}, \mathrm{CO}_{2}\right)(6.0$ vs $5.0 \mathrm{kPa} ; \mathrm{p}<0.01)$. They also had a more rapid increase in $\mathrm{Pa}_{2} \mathrm{CO}_{2}\left(0.3 v s 0.03 \mathrm{kPa}^{-} \mathrm{yr}^{-1} ; \mathrm{p}<0.01\right)$, but the difference in decline in $\mathrm{VC}\left(40\right.$ vs $\left.30 \mathrm{~mL} \cdot \mathrm{yr}^{-1}\right)$ was not significant. Initial $\mathrm{VC}<50 \%$ of predicted and/or $\mathrm{Pa}_{2} \mathrm{CO}_{2}>6 \mathrm{kPa}$ was associated with a poor prognosis.

In conclusion, annual decline in vital capacity was not abnormally rapid but annual increase in arterial carbon dioxide tension was higher in patients with a poor outcome. Initial determination of vital capacity and initial and repeated blood gas analysis appear to be useful in identifying high-risk postpolio patients. Eur Respir J., 1997; 10: 146-149.
Dept of Lung Medicine, University Hospital, Lund, Sweden.

Correspondence: B. Midgren

Dept of Lung Medicine

University Hospital

S-221 85 Lund

Sweden.

Keywords: Polio prognosis

respiratory failure

Received: April 71995

Accepted after revision August 141996

This study was financially supported by the Swedish Heart and Lung Foundation, the Swedish Society for Traffic and Polio Disabled and by the King Gustav V Research Foundation.
Chronic hypoventilation may develop several decades after the acute phase of poliomyelitis [1-7]. It is, however, still under debate whether the annual decline in vital capacity (VC) is more rapid than in the general population. Another explanation is that what we are now observing is a normal ageing process superimposed on the impairment of respiratory function from the acute phase of the disease. Most previous studies on lung function postpolio have been cross-sectional [5, 7-9], but two studies have analysed longitudinal data retrospectively. One study suggested a normal annual decline of lung function [3], and the other suggested an accelerated decline [4]. It is also necessary to know more about the value of initial lung function data and/or clinical history at the first contact with a respiratory clinic for the prediction of the later development of respiratory insufficiency.

In 1983, when no polio patients were on domiciliary assisted ventilation in our admission area we saw our first postpolio patient admitted as an emergency with life-threatening hypoventilation. This patient stimulated us to start this postpolio lung function study to determine whether similar situations could be foreseen or prevented.

Just prior to this episode, there had been a survey of general medical problems in polio survivors in our admission area [10]. This gave us an opportunity to approach the most severely disabled and offer them a pulmonary investigation and a regular follow-up of their respiratory function. This group is the basis of this prospective study of lung function versus clinical outcome in polio survivors.

The aims of the study were to investigate basal clinical and lung function data and the rate of decline in lung function in postpolio patients and to relate these findings to the occurrence of a subsequent poor outcome, defined as death from respiratory failure or a need for long-term assisted ventilation.

\section{Patients and methods}

In 1983, the total number of postpolio patients in our admission area (550,000 inhabitants) was estimated to be 350 [10]. A letter of invitation was sent to 80 patients, who were considered to be the most severely affected (kyphoscoliosis, bracing, wheel-chair bound, or with a history of assisted ventilation in the acute phase of the disease). Only half of these patients accepted the invitation but, during subsequent years, another 15 patients have visited our clinic because of more or less wellfounded suspicion of respiratory problems. Thus, a total cohort of 55 patients (about 15\% of the estimated postpolio population in our admission area) have been investigated at least once. 
Table 1. - Clinical and lung function data at the primary investigation for all patients $(n=55)$

\begin{tabular}{lc}
\hline Age at primary investigation yrs & $54 \pm 10$ \\
Age at onset of disease yrs & $11 \pm 8$ \\
$\mathrm{VC} \%$ pred & $58 \pm 20$ \\
$\mathrm{~Pa}, \mathrm{O}_{2} \mathrm{kPa}$ & $10.8 \pm 1.9$ \\
$\mathrm{~Pa}, \mathrm{CO}_{2} \mathrm{kPa}$ & $5.5 \pm 1.1$ \\
Assisted ventilation in the acute phase & $12 / 54$ \\
Bulbar involvement in the acute phase & $17 / 53$ \\
Trunkal involvement in the acute phase & $39 / 55$ \\
Thoracic scoliosis & $36 / 51$ \\
Dyspnoea on exertion & $26 / 50$ \\
Ex-smokers or current smokers & $20 / 53$
\end{tabular}

Data are presented as mean \pm SD, or as fraction where relevant. VC: vital capacity; $\mathrm{Pa}_{\mathrm{a}} \mathrm{O}_{2}$ : arterial oxygen tension; $\mathrm{Pa}_{\mathrm{a}} \mathrm{CO}_{2}$ : arterial carbon dioxide tension; $\%$ pred: percentage of predicted value.

The primary investigation comprised a medical history, blood gas analysis and spirometry. Spirometry was performed using a Vitalograph dry bellow spirometer. Blood gas samples were drawn from the radial artery with the patient in the sitting position. Initial lung function data and relevant details from the medical histories are presented in table 1.

Follow-up studies were performed with different intervals (6 months to $5 \mathrm{yrs}$ ), according to the investigator's discretion, but several patients were lost due to migration or death. Nevertheless, results for at least 5 (mean 8.9) yrs complete follow-up (average number of visits 5.3) are available for 31 patients. Linear regression analysis for each of these patients was used for the analysis of annual decline in VC. Evolution of arterial carbon dioxide tension $\left(\mathrm{Pa}_{\mathrm{a}}, \mathrm{CO}_{2}\right)$ was also analysed, with individual linear regression for patients without subsequent need for long-term ventilator therapy who had been followed-up for at least five years $(n=19)$, and for those of the ventilated patients who had been followedup for at least 2 years (average 6 yrs) before they needed long-term ventilator therapy $(n=10)$. Eight patients had also been followed-up for more than 1 year after starting domiciliary nocturnal assisted ventilation; the postventilator changes in their daytime arterial $\left(\mathrm{Pa}_{\mathrm{a}} \mathrm{CO}_{2}\right)$ were also analyzed.

Patients who started domiciliary assisted ventilation $(n=13)$ or who died from respiratory failure $(n=5)$, were grouped together as a "poor outcome" group $(n=17$; one overlap) and compared with the "good outcome" group (unventilated and surviving) with respect to their medical history and lung function data at the first investigation. For the poor outcome group, blood gas data were analysed only if they were obtained during clinical stability at least 1 year before the adverse event.

Statistical analyses were made with Student's t-test, Fisher's exact test, and linear regression analysis, where relevant. A p-value $<0.05$ was considered significant. The investigation was approved by the Medical Ethics Committee at the University of Lund, Sweden.

\section{Results}

\section{All patients}

$\mathrm{VC}$, arterial oxygen tension $\left(\mathrm{Pa}, \mathrm{O}_{2}\right)$, and $\mathrm{Pa}_{\mathrm{a}} \mathrm{CO}_{2}$ were similar for patients with and without a history of assisted
Table 2. - Comparison of patients with and without thoracic scoliosis

\begin{tabular}{|c|c|c|c|}
\hline & $\begin{array}{l}\text { Scoliosis } \\
(\mathrm{n}=36)\end{array}$ & $\begin{array}{c}\text { No scoliosis } \\
\quad(\mathrm{n}=15)\end{array}$ & p-value \\
\hline VC $\%$ pred & $49 \pm 16$ & $75 \pm 21$ & $<0.001$ \\
\hline$P_{\mathrm{a}, \mathrm{O}_{2}} \mathrm{kPa}$ & $10.3 \pm 2$ & $11.5 \pm 1.5$ & $<0.001$ \\
\hline $\mathrm{Pa}_{\mathrm{a}, \mathrm{CO}_{2} \mathrm{kPa}}$ & $5.7 \pm 1.2$ & $5.1 \pm 0.8$ & $<0.001$ \\
\hline $\begin{array}{l}\text { Annual decline in } \\
\mathrm{VC} \mathrm{mL} \cdot \mathrm{yr}^{-1}\end{array}$ & $33 \pm 38$ & $38 \pm 50$ & NS \\
\hline $\begin{array}{l}\text { Annual increase in } \\
P_{\mathrm{a},}, \mathrm{CO}_{2} \mathrm{kPa} \cdot \mathrm{yr}^{-1}\end{array}$ & $0.10 \pm 0.13$ & $0.18 \pm 0.46$ & NS \\
\hline
\end{tabular}

All data are from the primary investigation. Statistical analysis was made using Student's t-test (two-tailed). Values are presented as mean \pm SD. NS: nonsignificant. For further definitions see legend to table 1 .

ventilation or bulbar or trunkal involvement during the acute phase. Patients with scoliosis had a lower VC and a more severe disturbance in blood gas tensions (table 2 ), but their lung function did not deteriorate more rapidly.

There was a nonlinear negative relationship between $P$ a, $\mathrm{CO}_{2}$ and $\mathrm{VC}$ at the primary investigation, with 8 out of 10 hypercapnic patients having a VC less than $50 \%$ of predicted (fig. 1). The two hypercapnic patients with VC above $50 \%$ pred both had signs of bulbar poliomyelitis sequelae with dysphagia or dysarthria.

Male patients lost $\mathrm{VC}$ of, on average, $39 \mathrm{~mL} \cdot \mathrm{yr}^{-1}$ (95\% confidence interval $(95 \% \mathrm{CI}) 17-60)$ and females $30 \mathrm{~mL} \cdot \mathrm{yr}^{-1}$ (95\% CI 9-52), which is not significantly higher than figures for normal subjects above $55 \mathrm{yrs}$ of age (27 and $20 \mathrm{~mL} \cdot \mathrm{yr}^{-1}$ respectively) [11]. For patients with a good outcome, the annual change in $\mathrm{Pa}_{\mathrm{a}} \mathrm{CO}_{2}$ was barely different from zero (+0.03 kPa; CI -0.0004-0.05).

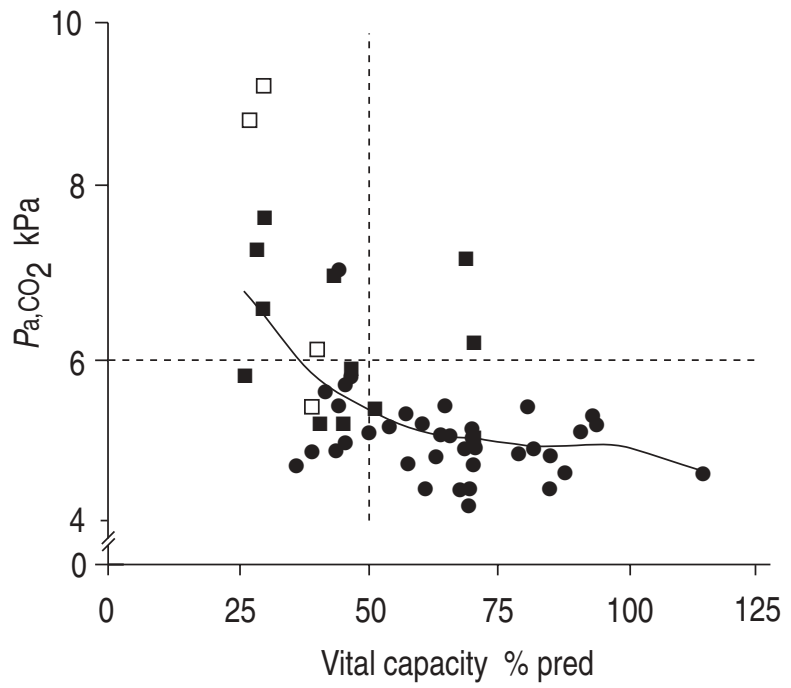

Fig. 1. - Relationship between vital capacity (VC) and arterial carbon dioxide tension $\left(\mathrm{Pa}_{\mathrm{a}}, \mathrm{CO}_{2}\right)$ at the primary investigation for patients where simultaneous spirometric and blood gas data were available $(\mathrm{n}=52)$. The horizontal broken line indicates the upper normal limit for $P \mathrm{a}, \mathrm{CO}_{2}$. The vertical broken line is arbitrarily drawn through $\mathrm{VC}$ $=50 \%$ of predicted. $\bullet$ : good outcome; $\mathbf{\square}$ : poor outcome, i.e. patients started on domiciliary assisted ventilation $(n=11)$ or patients who died from respiratory failure during the 11 year study period $(n=5) ; \square$ : patients who were followed-up for less than one year before the adverse event $(n=4)$. These observations were not included in the calculation of the curved line that represents the best curvilinear fit of the obserations. \% pred: percentage of predicted value. 
Table 3. - Comparison of patients with poor outcome $(n=17)$, compared with good outcome $(n=38)$.

\begin{tabular}{|c|c|c|c|}
\hline & $\begin{array}{l}\text { Poor } \\
\text { outcome }\end{array}$ & $\begin{array}{l}\text { Good } \\
\text { outcome }\end{array}$ & p-value \\
\hline $\begin{array}{l}\text { Age at primary } \\
\text { investigation yrs } \\
\text { Age at onset }\end{array}$ & $53 \pm 11$ & $55 \pm 10$ & 0.53 \\
\hline of disease yrs & $8 \pm 7$ & $12 \pm 8$ & 0.2 \\
\hline VC \% pred & $43 \pm 16$ & $65 \pm 17$ & $<0.01$ \\
\hline$P \mathrm{a}, \mathrm{O}_{2} \quad \mathrm{kPa}$ & $9.9 \pm 1.5$ & $11 \pm 1.2$ & $<0.05$ \\
\hline$P \mathrm{a}, \mathrm{CO}_{2} \quad \mathrm{kPa}$ & $6.0 \pm 1.0$ & $5.0 \pm 0.5$ & $<0.001$ \\
\hline $\begin{array}{l}\text { Annual decline in } \\
\text { VC } \mathrm{mL} \cdot \mathrm{yr}^{-1}\end{array}$ & $\begin{array}{l}40 \pm 33 \\
(n=11)\end{array}$ & $\begin{array}{l}30 \pm 43 \\
(n=20)\end{array}$ & 0.5 \\
\hline $\begin{array}{l}\text { Annual increase in } \mathrm{Pa}_{\mathrm{a}}, \mathrm{CO}_{2} \\
\mathrm{kPa} \cdot \mathrm{yr}^{-1}\end{array}$ & $\begin{array}{r}0.3 \pm 0.4 \\
(n=10)\end{array}$ & $\begin{array}{l}0.03 \pm 0.06 \\
(n=19)\end{array}$ & $<0.01$ \\
\hline $\begin{array}{l}\text { Assisted ventilation } \\
\text { in the acute phase }\end{array}$ & $5 / 17$ & $7 / 36$ & 0.44 \\
\hline $\begin{array}{l}\text { Bulbar involvement } \\
\text { in the acute phase }\end{array}$ & $8 / 17$ & $9 / 35$ & 0.20 \\
\hline $\begin{array}{l}\text { Trunkal involvement } \\
\text { in the acute phase }\end{array}$ & $13 / 17$ & $25 / 37$ & 0.75 \\
\hline Thoracic scoliosis & $14 / 16$ & $21 / 34$ & 0.1 \\
\hline Dyspnoea on exertion & $12 / 15$ & $14 / 34$ & 0.015 \\
\hline $\begin{array}{l}\text { Ex-smokers or current } \\
\text { smokers }\end{array}$ & $6 / 17$ & $14 / 35$ & 0.77 \\
\hline
\end{tabular}

Data are presented as mean $\pm \mathrm{SD}$, or as fractions where relevant. All data are from the primary investigation. Blood gas data are included in the analysis only if they were obtained at least 1 year before the adverse event. Statistical analysis was made using Student's t-test and Fisher's exact test (two-tailed). For definitions see legend to table 1 .

\section{"Poor outcome" group}

At the primary investigation, patients with a subsequent "poor outcome" had lower $\mathrm{VC}$ and $\mathrm{Pa}, \mathrm{O}_{2}$ and higher $\mathrm{Pa}_{\mathrm{a}} \mathrm{CO}_{2}$ than the other patients (table 3 ). Their decline in $\mathrm{VC}$ was 40 vs $30 \mathrm{~mL} \cdot \mathrm{yr}^{-1}$ in the good outcome group $(\mathrm{p}=0.5)$. Their $\mathrm{Pa}_{\mathrm{a}} \mathrm{CO}_{2}$ rose significantly more $\left(0.3\right.$ vs $\left.0.03 \mathrm{kPa} \cdot \mathrm{yr}^{-1}, \mathrm{p}<0.01\right)$. The patient with the most rapid increase in $\mathrm{Pa}_{\mathrm{a}} \mathrm{CO}_{2}$ had bulbar poliomyelitis sequelae and later started nocturnal assisted ventilation in spite of a VC of more than $3 \mathrm{~L}$. A history of assisted ventilation, bulbar or trunkal involvement during the acute phase of the disease was otherwise no more common in the group with poor outcome.

To the best of our knowledge, these 13 patients on domiciliary assisted ventilation represent the total number of such postpolio patients in our admission area during the 11 year study period. This gives an annual incidence of 0.2 per 100,000 inhabitants or 3.5 per 1,000 polio survivors. In five cases, domiciliary assisted ventilation was initiated on vital indication, and in the remaining cases it was used to relieve the patients from disturbing symptoms of hypoventilation (daytime somnolence, morning headache). These symptoms were recognized at very different levels of $P \mathrm{a}, \mathrm{CO}_{2}$. Average daytime $P \mathrm{a}, \mathrm{CO}_{2}$ at the time of commencement of domiciliary assisted ventilation (acute and elective cases) was $7.6 \mathrm{kPa}$ (range $6.1-10.5 \mathrm{kPa}$ ), and average $\mathrm{VC}$ was $35 \%$ pred (range $18-56 \%$ pred, plus the patient with bulbar disease with VC $72 \%$ pred). In five cases with symptoms of hypoventilation in spite of near normal $\mathrm{Pa}_{\mathrm{a}} \mathrm{CO}_{2}$, transcutaneous capnometry was used during sleep [12] to confirm that nocturnal hypoventilation could explain their current

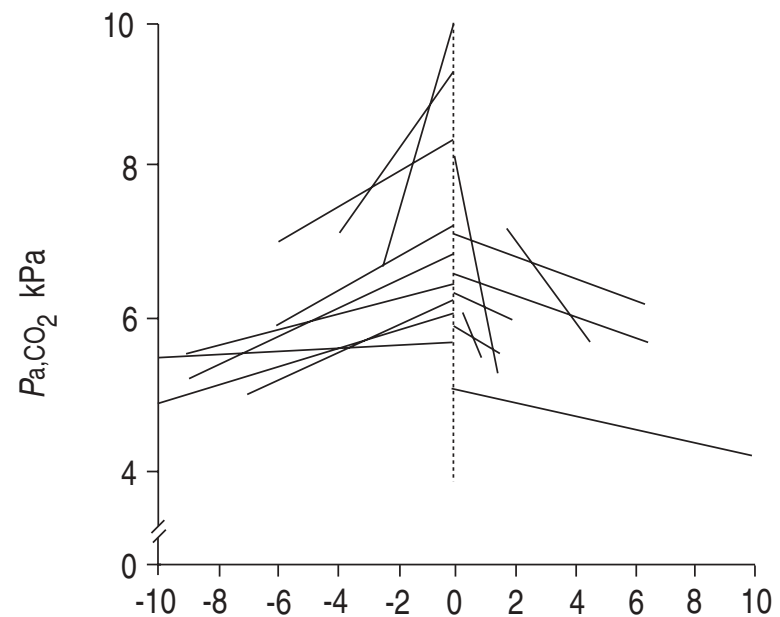

Before and after starting nocturnal assisted ventilation yrs

Fig. 2. - Change in arterial carbon dioxide tension $\left(P \mathrm{a}, \mathrm{CO}_{2}\right)$ for those patients who started nocturnal assisted ventilation and who were followed-up for at least 2 years before $(n=9)$ and/or 1 year afterwards $(n=8)$. Regression lines are drawn for each patient.

symptoms. The diagnosis of chronic hypoventilation was finally accepted if nocturnal assisted ventilation resolved the symptoms, which it did in all cases in which is was tried. Elevation of $\mathrm{Pa}_{2} \mathrm{CO}_{2}$ was never the sole criterion for domiciliary assisted ventilation.

The evolution of $\mathrm{Pa}_{\mathrm{a}} \mathrm{CO}_{2}$ before $(\mathrm{n}=9)$ and after $(\mathrm{n}=8)$ commencement of domiciliary nocturnal assisted ventilation is shown in figure 2 . These changes in $\mathrm{Pa}_{\mathrm{a}} \mathrm{CO}_{2}$ were not accompanied by any measurable changes in VC.

\section{Discussion}

Although we aimed to find the most severely disabled postpolio patients in our admission area, we cannot claim total coverage of the target group. This weakness is however, shared by all studies on postpolio patients. Another Swedish group aimed to find all postpolio patients in their admission area [9]. However, the alleged "total" prevalence figure (40 patients out of 450,000 inhabitants) in that study was actually less than the prevalence of identified "severe cases" in the present study (55 out of 550,000). Other authors generally do not comment on the representativity of their study groups. The present patients had a VC of $58 \%$ pred, a figure strikingly similar to that from other studies of the most severely affected patients $[2,7,8]$. We therefore believe that our results are reasonably valid for those postpolio patients who are most likely to be seen in a respiratory clinic.

The present study failed to show a more rapid decline in $\mathrm{VC}$ (expressed as $\mathrm{mL} \cdot \mathrm{yr}^{-1}$ ) in postpolio patients as compared to normal subjects. Whether this is a true finding or if we are experiencing a type II error, we do not know. Expressing the decline as a percentage of baseline, as some authors do [3, 4], would have given more "impressive" figures. This may, however, not be the best way of presenting data, since annual decline in VC $\left(\mathrm{mL} \cdot \mathrm{yr}^{-1}\right)$ does not normally fall (it actually increases) with age [13]. The decline in VC was not 
more rapid in patients with a poor outcome, nor in scoliotics. In contrast to this, patients who later needed domiciliary nocturnal ventilation had a significantly larger annual increase in $P \mathrm{a}, \mathrm{CO}_{2}$. This elevation was readily reversed by the assisted ventilation.

Other features in the poor outcome group were a lower VC and $\mathrm{Pa}, \mathrm{O}_{2}$ and higher $\mathrm{Pa}_{\mathrm{a}} \mathrm{CO}_{2}$ at the primary investigation. It must be emphasized that we analysed only those values that were documented at least 1 year (average $4.3 \mathrm{yrs}$ ), i.e. during clinical stability, before commencement of domiciliary assisted ventilation or death from respiratory failure.

A history of assisted ventilation or bulbar or trunkal involvement was not more common in patients with a poor outcome. This is in contrast to what other authors have found [5]. The reason is probably a selection bias, since we recruited mainly patients with "poor history". Hence, the good outcome group included many patients with "poor history".

Another contrast to previous research [14] is that we found no difference in lung function between the patients who did and those who did not require assisted ventilation at the time of their acute disease. This may be due to a "survival of the fittest" effect in patients in the present study. Another finding in the study by HowARD et al. [14] was that a "precipitating factor" accounted for respiratory deterioration in more than half of the cases. This was not the case in the present series (albeit much smaller), in which we actively questioned the patients about the insidious and nonspecific symptoms of hypoventilation. We, thereby, probably prevented the development of acute respiratory failure in several patients, by giving them domiciliary assisted ventilation on an elective basis.

From figure 1, it can be seen that a poor outcome was strongly associated with hypercapnia and/or a low $\mathrm{VC}$ at the primary investigation. Only two patients with normal $\mathrm{Pa}_{\mathrm{a}} \mathrm{CO}_{2}$ and $\mathrm{VC}$ above $50 \%$ pred (lower right quadrant $=$ "safe" quadrant) had a poor outcome (nocturnal domiciliary assisted ventilation 6 and 10 yrs later). More than half of the group with hypercapnia and/or VC below $50 \%$ of predicted ("dangerous" quadrants) had a poor outcome. The recommendation of $\mathrm{BACH}$ and Alba [6] that "any patient with less than $50 \%$ of predicted normal supine vital capacity should undergo oxygen saturation $\left(\mathrm{Sa}, \mathrm{O}_{2}\right)$ and $\mathrm{Pa}, \mathrm{CO}_{2}$ monitoring during sleep" is, therefore, supported by these results. They also state that "hypercapnia is likely when the vital capacity falls below $55 \%$ of predicted normal" [6], a statement that is wellsupported by the present data (fig. 1).

It must be emphasized that the term "poor outcome" does not imply that domiciliary assisted ventilation in itself is a bad thing. This type of treatment is quite consistent with a high quality of life $[6,15]$. Twelve of our 13 ventilated patients (mean age $58 \mathrm{yrs}$ ) are still alive, all but one use their ventilator less than $10 \mathrm{~h} \cdot \mathrm{day}^{-1}$, seven use noninvasive methods, and four are still gainfully employed. Nevertheless it seems justified to give the ventilated group and the deceased group the common label "poor outcome", since they have many properties in common. Had the ventilated patients been left untreated, we are convinced that only five would still be alive.

In conclusion, annual decline in vital capacity in postpolio patients appears not to differ significantly from that of normal subjects. The decline was not more rapid in patients with a poor outcome, but their annual increase in arterial carbon dioxide was more pronounced. A poor outcome (sometimes many years later) occurred in more than half of the patients with a vital capacity below $50 \%$ of predicted and/or an arterial carbon dioxide tension above $6 \mathrm{kPa}$ at the primary investigation.

\section{References}

1. Hamilton EA, Nichols PJR, Tait GBW. Late onset of respiratory insufficiency after poliomyelitis. Ann Phys Med 1970; 10: 223-229.

2. Lane DJ. Hazleman B, Nichols PJR. Late onset respiratory failure in patients with previous poliomyelitis. $Q$ J Med 1974; 172: 551-568.

3. Fischer DA. Poliomyelitis: late respiratory complications and management. Orthopedics 1985; 8: 891-894.

4. Bach JR, Alba AS. Bohatiuk G, Saporito L, Lee M. Mouth intermittent positive pressure ventilation in the management of postpolio respiratory insufficiency. Chest 1987; 91: 859-864.

5. Dean E, Ross J, Road JD, Courtenay L, Madill KJ. Pulmonary function in individuals with a history of poliomyelitis. Chest 1991; 100: 118-123.

6. Bach JR, Alba A. Pulmonary dysfunction and sleepdisordered breathing as postpolio sequelae: evaluation and management. Orthopedics 1991; 14: 1329-1337.

7. Dolmage TE, Avendano MA, Goldstein RS. Respiratory function during wakefulness and sleep among survivors of respiratory and nonrespiratory poliomyelitis. Eur Respir J 1992; 5: 864-870.

8. Borg K, Kaijser L. Lung function in patients with prior poliomyelitis. Clin Physiol 1990; 10: 201-212.

9. Blomstrand A, Bake B. Postpolio lung function. Scand J Rehab Med 1992; 24: 43-49.

10. Thufvesson A-K. Polioskadade - finns de? (A social medicine research of polio patients in Malmöhus county). SVCR Series, Swedish Central Committee for Rehabilitation, 1984.

11. Sherrill DL, Lebowitz MD, Knudson RJ, Burrows B. Longitudinal methods for describing the relationship between pulmonary function, respiratory symptoms and smoking in elderly subjects: the Tucson Study. Eur Respir J 1993: 6: 342-348.

12. Midgren B, Airikkala P, Ryding E, Elmqvist D. Transcutaneous $\mathrm{CO}_{2}$ monitoring and disordered breathing during sleep. Eur J Respir Dis 1984; 65: 521-528.

13. Ware JH, Dockery DW, Louis TA, Xu X, Ferris Jr BG, Speizer FE. Longitudinal and cross-sectional estimates of pulmonary function decline in never-smoking adults. Am J Epidemiol 1990; 132: 685-700.

14. Howard RS, Wiles CM, Spencer GT. The late sequelae of poliomyelitis. Q J Med 1988; 251: 219-232.

15. Bach JR, Campagnolo DI. Psychosocial adjustment of postpoliomyelitis ventilator-assisted individuals. Arch Phys Med Rehabil 1992; 73: 934-939. 